\title{
Impressões foliares pleistocenas de Malvaceae na área de abrangência do Aprovei- tamento Hidroelétrico Jirau, Rondônia, Brasil
}

\author{
Maria S. BORGES ${ }^{1}$, Etiene F. PIRES ${ }^{1}$, Carlos R. BOELTER ${ }^{2}$, Maria E.N.S. MENESES ${ }^{1}$, Átila A.S. Da ROSA ${ }^{3}$, \\ Alcemar R. MARTELLO ${ }^{4}$ \& Ruben A. BOELTER ${ }^{5}$
}

1. Universidade Federal do Tocantins. Rua 07 Qd. 15 s/noำ Jardim dos Ipês, CEP 77500-000, Porto Nacional, T0, Brasil. E-mail: mariasuete@ msn.com, etienefabbrin@uft.edu.br, mariaecilene@yahoo.com.br.

2. Instituto Nacional de Pesquisas na Amazônia. Caixa Postal 478, Manaus, AM, Brasil. E-mail: leleuboelter@gmail.com.

3. Universidade Federal de Santa Maria. Av. Roraima, 1000, Camobi, CEP 97105-900, Santa Maria, RS, Brasil. E-mail: atila@smail.ufsm.br.

4. Universidade Estadual do Paraná. Caixa Postal 241, CEP 84600-000 União da Vitória, PR, Brasil. E-mail: armartello@hotmail.com.

5. Universidade Federal da Fronteira Sul, Campus de Realeza. Caixa Postal 18, CEP 89802-210, Chapecó, SC, Brasil. E-mail: rubinhoboelter@hotmail.com.

Recebido em 11/2013. Aceito para publicação em 11/2014.

Versão online publicada em 04/12/2014 (www.pesquisasemgeociencias.ufrgs.br)

\begin{abstract}
Resumo - Este trabalho tem como objetivo descrever a morfologia foliar e realizar o reconhecimento taxonômico de dez impressões foliares de angiospermas coletadas em afloramento da Formação Rio Madeira na área de abrangência do Aproveitamento Hidrelétrico (AHE) Jirau, resgatadas pela equipe do Programa de Investigação, Salvamento e Monitoramento Paleontológico. Devido à preservação e com base na descrição morfológica, os espécimes foram identificados até o nível de gênero. Todos os espécimes mostram caracteres que indicam sua relação com a família Malvaceae, nove deles com o gênero Luehea e um exemplar ao gênero Theobroma. Duas amostras foram retiradas da camada inferior àquela que concentra os fósseis, com o objetivo de realizar datação através do método "Accelerator Mass Spectrometry" (AMS C ${ }^{14}$ ). A datação apontou idades entre 15.910 e 14.850 anos calibrados AP. Os dois gêneros registrados são comuns na cobertura florestal atual na região do AHE Jirau, e a sua presença é também confirmada pelos dados palinológicos obtidos para a parte superior da Formação Rio Madeira.
\end{abstract}

Palavras chave: Formação Rio Madeira, Pleistoceno, impressões foliares, Malvaceae.

\begin{abstract}
Pleistocene leaf impressions of Malvaceae in the CATCHMEnt area of the JiRAu HydroeleTRIC DAM, RoNDÔNIA, BRAZIL.This paper aims to describe the morphology and taxonomic identification of ten angiosperm leaf impressions collected in Rio Madeira Formation outcrop in the area from Jirau Hydroeletric Dam, found by the team of Paleontological Research, Monitoring and Rescue Program. Due to the preservation and based on morphology, the specimens were identified at the genus level. All specimens belong to the family Malvaceae, and nine specimens were identified as Luehea and one specimen belongs to the genus Theobroma. Two samples were taken from the layer below to the fossiliferous bed, in order to carry dating by method "Accelerator Mass Spectrometry" (AMS C ${ }^{14}$ ). The dating pointed ages between 15.910 and 14.850 years calibrated $\mathrm{BP}$. The genus reported here are common in current forest cover in the region of AHE Jirau, and their presences are also confirmed by palynological data obtained for the upper part of the Rio Madeira Formation.
\end{abstract}

Keywords: Rio Madeira Formation, Pleistocene, Leaf impressions, Malvaceae.

\section{Introdução}

A Bacia Sedimentar do Abunã consiste em uma depressão sedimentar quaternária alongada, medindo em torno de $65 \mathrm{~km}$ de comprimento e $30 \mathrm{~km}$ de largura, localizada na porção NW do Estado de Rondônia, distante aproximadamente $190 \mathrm{~km}$ de Porto Velho. Parte desta bacia se estende nas direções SW e WSW para o território boliviano.

Segundo Nascimento \& Holanda (2006), o conhecimento paleontológico para o Estado de Rondônia derivou da intensa atividade garimpeira na década de 80 , pois de acordo com Sadeck (1999), a camada portadora de ouro, denominada localmente como "mucururu" consiste na mesma camada onde se encontram os fósseis.
Contudo, trabalhos de cunho paleontológico realizados na Bacia de Abunã consistem em registros pontuais, sendo basicamente dissertações de mestrado, resumos apresentados em congressos e relatórios técnicos. Destes estudos prévios são conhecidos registros de fragmentos ósseos, atribuídos a mamíferos (Adamy\& Pereira, 1991; Sant'Anna Filho et al., 1996; Sant'Anna Filho \& Schmitt, 1999; Sant'Anna Filho \& Vidal, 1999; Nascimento et al., 2003; Góis et al., 2004; Holanda et al., 2004; Góis, 2005; Cozzuol et al., 2006; Holanda \& Cozzuol, 2005, 2006; Holanda, 2007; Góis \& Scillato-Yané, 2008; Holanda et al., 2011; Góis et al., 2012), um crocodilomorpha (Nascimento et al., 2005) e testudíneos (Nascimento \& Holanda, 2006).

Os fósseis vegetais que ocorrem na Bacia de Abu- 
nã são pouco conhecidos, sendo que os registros são realizados de maneira indireta, em conjunto com achados de vertebrados fósseis, onde foram descritas ocorrências de impressões foliares, lenhos carbonizados e palinomorfos (Holanda, 2007; Nascimento, 2008; Silva et al., 2010). Em um dos trabalhos mais recentes de resgate paleontológico realizado na região de Porto Velho (RO) foram encontradas impressões foliares de angiospermas e caules permineralizados de grande porte, ainda não apresentados formalmente (Nascimento et al., 2009).

Com relação à área estudada, o Aproveitamento Hidrelétrico (AHE) Jirau está sendo implantado na calha do rio Madeira, afluente da margem direita do rio Amazonas. Seu limite a montante situa-se a cerca de $15 \mathrm{~km}$ da foz do rio Abunã e da fronteira Brasil-Bolívia, próximo à localidade de Abunã. 0 limite a jusante localiza-se no conjunto de ilhas formadas pela Ilha do Padre, Ilha da Formiga, Cachoeira do Inferno e a Ilha Pequena, entre as localidades de Jirau e Jaci Paraná (Silva et al., 2010).

Este trabalho tem o objetivo de descrever a morfologia e realizar o reconhecimento taxonômico de impressões foliares de angiospermas coletadas em afloramento da Formação Rio Madeira na área de abrangência do AHE Jirau, resgatadas pela equipe do Programa de Investigação, Salvamento e Monitoramento Paleontológico daquele empreendimento.

\section{2 Área, materiais e métodos}

\subsection{Características gerais da área}

Segundo o levantamento do IBGE (1992) e RADAMBRASIL (1978), a vegetação nativa presente na região consiste em uma densa floresta tropical, com características moderadamente sazonais, com elevações que variam de 100 a $600 \mathrm{~m}$. 0 clima da região é considerado como tropical úmido - Awi (Koppen) (Ferraz et al., 2005). Nota-se na região uma forte sazonalidade na distribuição da precipitação, com o período chuvoso (novembro-abril) apresentando totais mensais acima de $200 \mathrm{~mm} / \mathrm{mês}$. A estação menos chuvosa estende-se de maio a outubro, com um pequeno período de chuvas entre junho-agosto. A temperatura do ar, para o mesmo período, mostra também uma sazonalidade, sendo outubro o mês mais quente, com temperatura média de $25,6^{\circ} \mathrm{C}$, e julho, o mês mais frio, com temperatura média próxima a $22,7^{\circ} \mathrm{C}$ (Culf et al., 1996; Von Randown et al., 2004).

\subsection{Geologia}

A Bacia Sedimentar do Abunã foi individualizada no projeto RADAMBRASIL (1978), que apontou a ocorrência da Formação Solimões (Plioceno Superior) como correspondendo ao Cenozoico basal, seguida por sedimentos fluviais e fluvio-lacustres do Pleistoceno Superior (Formação Içá) e aluviões recentes. Após este trabalho, outros autores propuseram novas unidades e divisões litoestratigráficas para a bacia. No quadro 1 estão sumarizadas as propostas litoestratigráficas aqui apresentadas.

Adamy \& Romanini (1990) e Adamy \& Pereira (1991) renomearam as formações já estabelecidas, designando como "Cobertura Cenozóica" o pacote composto consecutivamente, da base ao topo, pelas formações Solimões e Jaci-Paraná (Pleistoceno-Holoceno) e depósitos sedimentares de aluviões atuais.

A parte inferior da Formação Jaci-Paraná, constituída por depósitos essencialmente fluviais, foi separada por Rizzotto (2005), e atribuída à Formação Rio Madeira, de idade Pleistoceno Superior-Holoceno, excluindo a Formação Solimões para a bacia. A Formação Jaci-Paraná ficou limitada aos depósitos suprajacentes de idade holocena.

Quadros et al. (2006) analisaram a Formação Rio Madeira e sugerem que esta é composta por duas unidades: a parte inferior, constituída por sedimentos argilosos, de coloração cinza-grafite a cinza claro, e sedimentos argilo-siltosos e argilo-arenosos, com conteúdo paleontológico representado por folhas e outros fragmentos vegetais; e a parte superior, denominada "mucururu" - denominação estabelecida por Costa (1991)que consiste em cascalho com matriz arenosa, com registro de fósseis pleistocenos. No topo da sequência sedimentar, encontra-se depositado um expressivo pacote de argila siltosa amarela, com frequentes depósitos de paleocanal.

Considerando-se a localidade estudada, Silva et al. (2010), em um trabalho arqueológico, mapearam seis unidades estratigráficas na área do Canteiro de Obras da AHE Jirau e entorno: Formação Jaci-Paraná, Formação Palmeiral, Formação Rio Madeira, cobertura dedrito-laterítica, granitoides anorogênicos e sedimentos aluvionares.

A Formação Jaci-Paraná qualificada como a mais expressiva das ocorrentes na área, foi caracterizada pela presença de depósitos pouco espessos de sedimentos síltico-argilosos a argilosos, de coloração acinzentada a amarelada, com lentes de areias ferruginosas e friáveis e conglomerados com rara estratificação plano-paralela. Os autores sugerem que o paleoambiente era caracterizado por depósitos de planície de inundação com eventuais canais, de idade pleistocena, já descritos por Quadros \& Rizzotto (2007).

A Formação Palmeiral, de idade neoproterozoica, caracterizada como depósitos fluviais (Silva et al., 2010), possui estratificação cruzada, ortoconglomerados com clastos arredondados de quartzo e quartzo-arenito, além de arenitos maciços. Bahia \& Pedreira (2007) assumem que suas litofácies caracterizam um sistema fluvial anastomosado ou em leque aluvial submetido a uma inversão de relevo.

Quadros \& Rizzotto (2007) descrevem a Suíte Intrusiva São Lourenço-Caripunas como formada por rochas granitoides anorogênicas, representadas por 
matacões rochosos parcialmente situados em trechos encachoeirados do rio Madeira. Os autores identificaram também a presença da Formação Rio Madeira, onde registram a presença de fósseis de megafauna pleistocena. Por fim, registram a ocorrência de Coberturas Detrito-Lateríticas, caracterizadas por depósitos argilo-arenosos ou síltico-arenosos ricos em concreções ferruginosas, com idade cenozoica estimada, enquanto os sedimentos aluvionares são depósitos de areias inconsolidadas holocenas.

A integração entre os dados geológicos de superfície e subsuperfície permitiu reconhecer a extensão lateral e vertical dos depósitos sedimentares na região estudada, a variabilidade de sua espessura, e a interdigitação entre litofácies recorrentes da Formação Rio Madeira (FRM). A FRM assenta-se discordantemente sobre o embasamento cristalino, constituído por rochas graníticas e metamórficas de alto grau, atingindo profundidades de até $85 \mathrm{~m}$ nos baixios estruturais, enquanto as rochas pré-cambrianas afloram em outras porções da área analisada. Os depósitos de canal e planície de inundação puderam ser reconhecidos através da descrição de testemunhos de sondagens geotécnicas, e da descrição de perfis nas áreas aflorantes (Da-Rosa et al., 2011).

Até o momento, segundo Holanda (2007), são citadas na literatura especializada três localidades fossilíferas com níveis aflorantes que podem ser incluídos na Formação Rio Madeira, todas associadas aos garimpos. Estas localidades estão representadas na margem direita do rio, sendo conhecidas como: Araras/Periquitos, nas cercanias do município de Nova Mamoré (Adamy\& Pereira, 1991; Sant'Anna Filho et al., 1996), Taquara, localizada no município de Porto Velho (Nascimento et al, 2003), e Prainha, no distrito de Mutum-Paraná (Sant'Anna Filho et al., 1996).

Quadro 1. Correlação das propostas litoestratigráficas apresentadas.

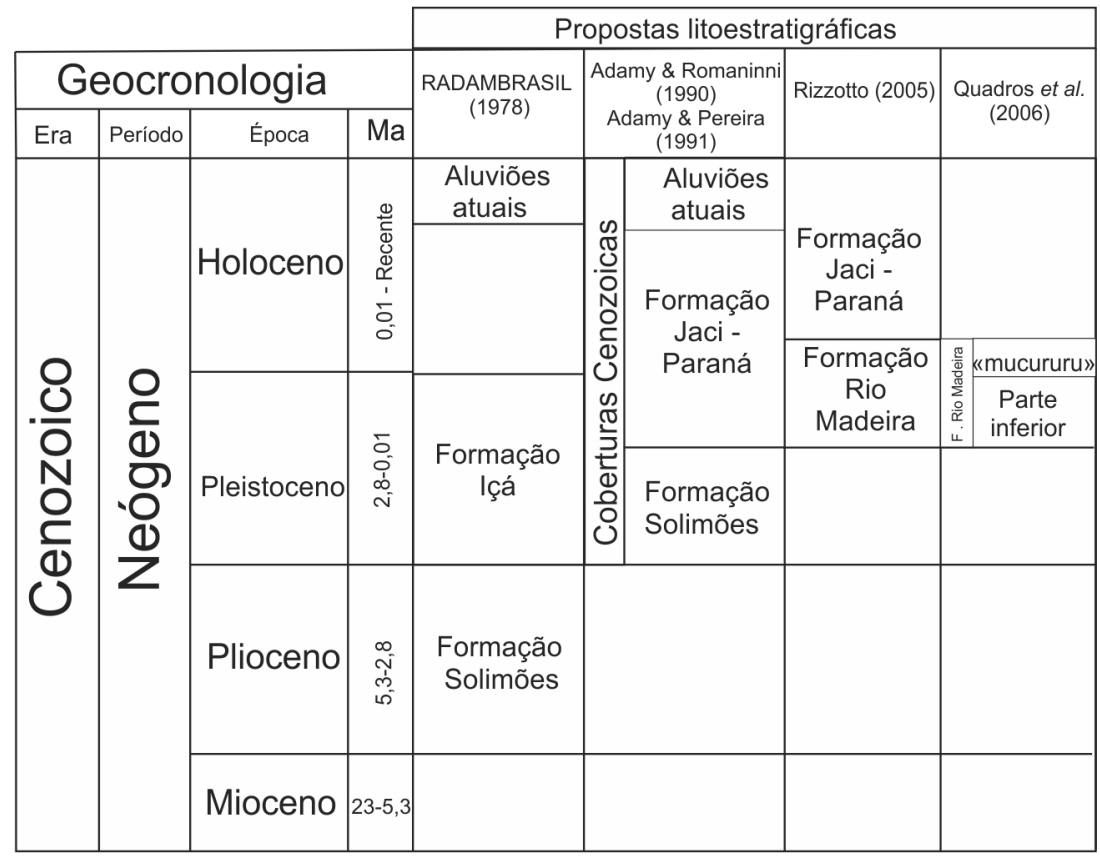

\subsection{Materiais e métodos}

Os fósseis vegetais aqui analisados consistem em 10 impressões foliares em bom estado de preservação. As amostras foram submetidas a tratamento curatorial e, para fins de conservação, com um pincel no 0 e uma agulha histológica retirou-se o excesso de sedimento que recobria as impressões. Após, cada espécime recebeu uma fina camada de verniz (Sparlack Copal, de coloração marrom claro), com a ajuda de um pincel $n$ o 0 . Posteriormente as amostras foram numeradas e registradas no livro tombo do Laboratório de Paleobiologia da Universidade Federal do Tocantins, sob a sigla UFT. 0 material foi doado à Coleção Paleontológica da Universidade de Rondônia, registrados no livro tombo recebendo numeração sequencial sob a sigla UNIR-PB.

As análises morfológicas foram realizadas com o uso de estereomicroscópio Inalh, MSZ-200, e as me- dições foram obtidas com a utilização de paquímetro analógico Starrett 799.

A descrição morfológica dos espécimes foi realizada através de metodologia proposta por Ellis et al. (2009). Os espécimes foram comparados com espécies atuais representantes da flora amazônica, através de consulta ao material depositado no herbário do INPA (Instituto Nacional de Pesquisas da Amazônia) e com o material digital disponibilizado pelo New York Botanical Garden (2013).

Para a descrição, as impressões foram fotografadas e a partir das fotografias digitais foram desenhadas no programa Corel Draw e comparadas com espécimes atuais também fotografados e redesenhados no mesmo programa (Fig. 2).

A descrição dos espécimes UNIR-PB-0008 A e UNIR-PB-0008 B foi realizada em conjunto, pois os espécimes são contrapartes e suas características 
preservaram-se em ambas as faces. Já nos espécimes UNIR-PB-0001 e UNIR-PB-0004, embora se configurem como contrapartes, a preservação é diferenciada e não permite que se observem as mesmas características nos dois espécimes, sendo que por este fato, são descritos separadamente.

Duas amostras de sedimento da camada inferior àquela que contém os fósseis (nível de "argila orgânica", Fig. 1CD), foram coletadas objetivando a aquisição de dados absolutos de idade. As amostras foram coletadas no mesmo nível, sendo retiradas com o auxílio de uma espátula de plástico. Em seguida, o material foi acondicionado em sacos plásticos e devidamente identificado. Não foi possível realizar datação na camada fossilífera, pois esta não contém matéria orgânica preservada. A datação foi realizada no laboratório Beta Analytic Inc., Miami, Florida, EUA, através do método "Accelerator Mass Spectrometry" (AMS), ou espectrometria de aceleração de massa. Este método utiliza a meia idade do isótopo $\mathrm{C}^{14}$ contido na amostra, para fornecer uma datação absoluta. A Idade Radiocarbônica Convencional é o resultado alcançado após a aplicação de correções para explicar as diferenças de fracionamento isotópico entre a amostra e a percentagem de carbono moderna (pMC). A Idade Radiocarbônica Convencional é citada como "BP" ou "AP" (Before Present: Antes do Presente), sendo que a palavra "Presente" refere-se ao ano de 1950 da Era Cristã para efeitos de datação radiocarbônica.

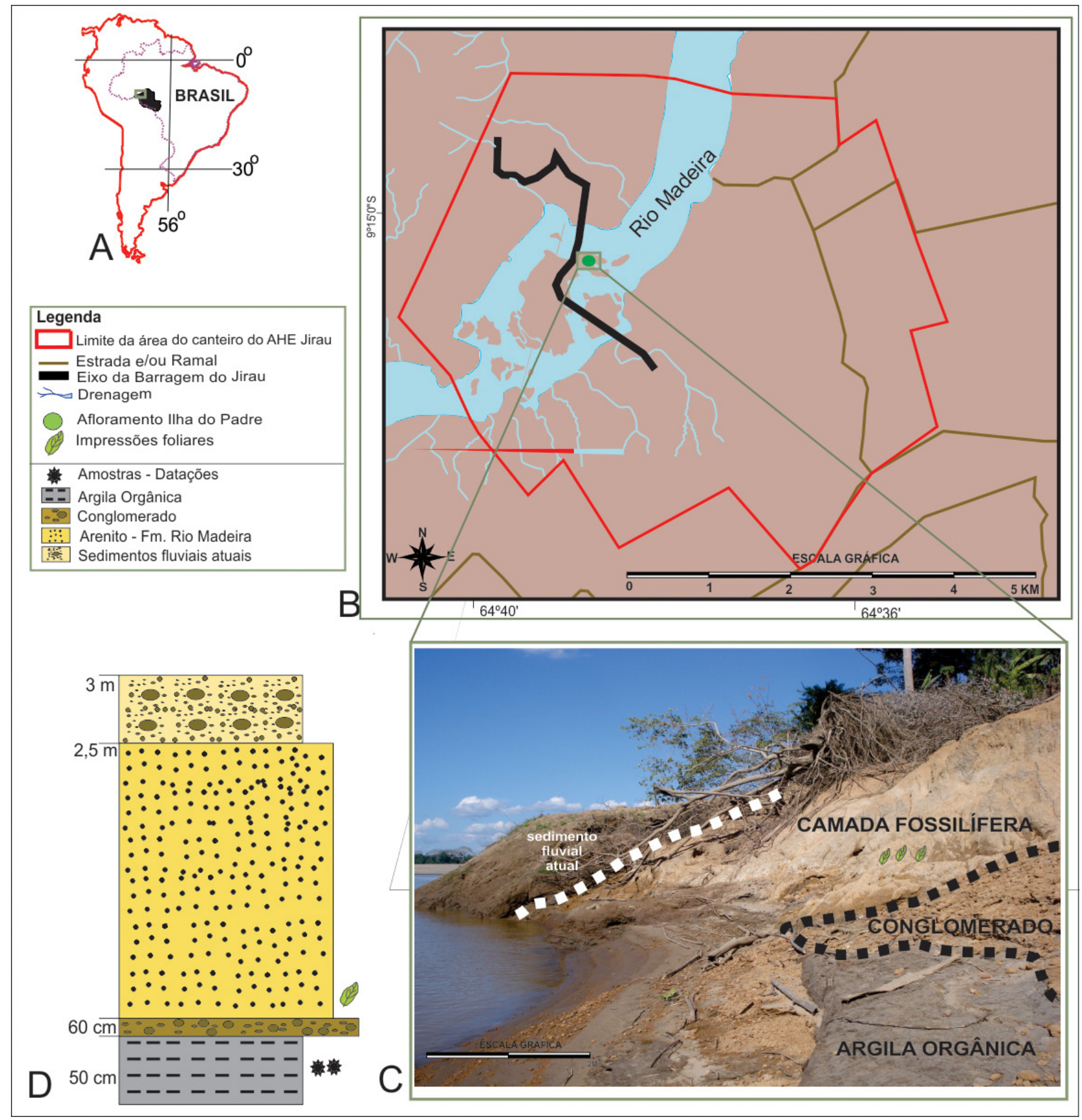

Figura 1. Mapa de localização. A) Mapa da América do Sul, com a indicação do Estado de Rondônia; B) Área do Canteiro de Obras para instalação do AHE Jirau, com a indicação da localização do afloramento Ilha do Padre; C) Detalhe do afloramento, com a individualização das camadas sedimentares e localização dos fósseis; D) Perfil geológico do afloramento. 


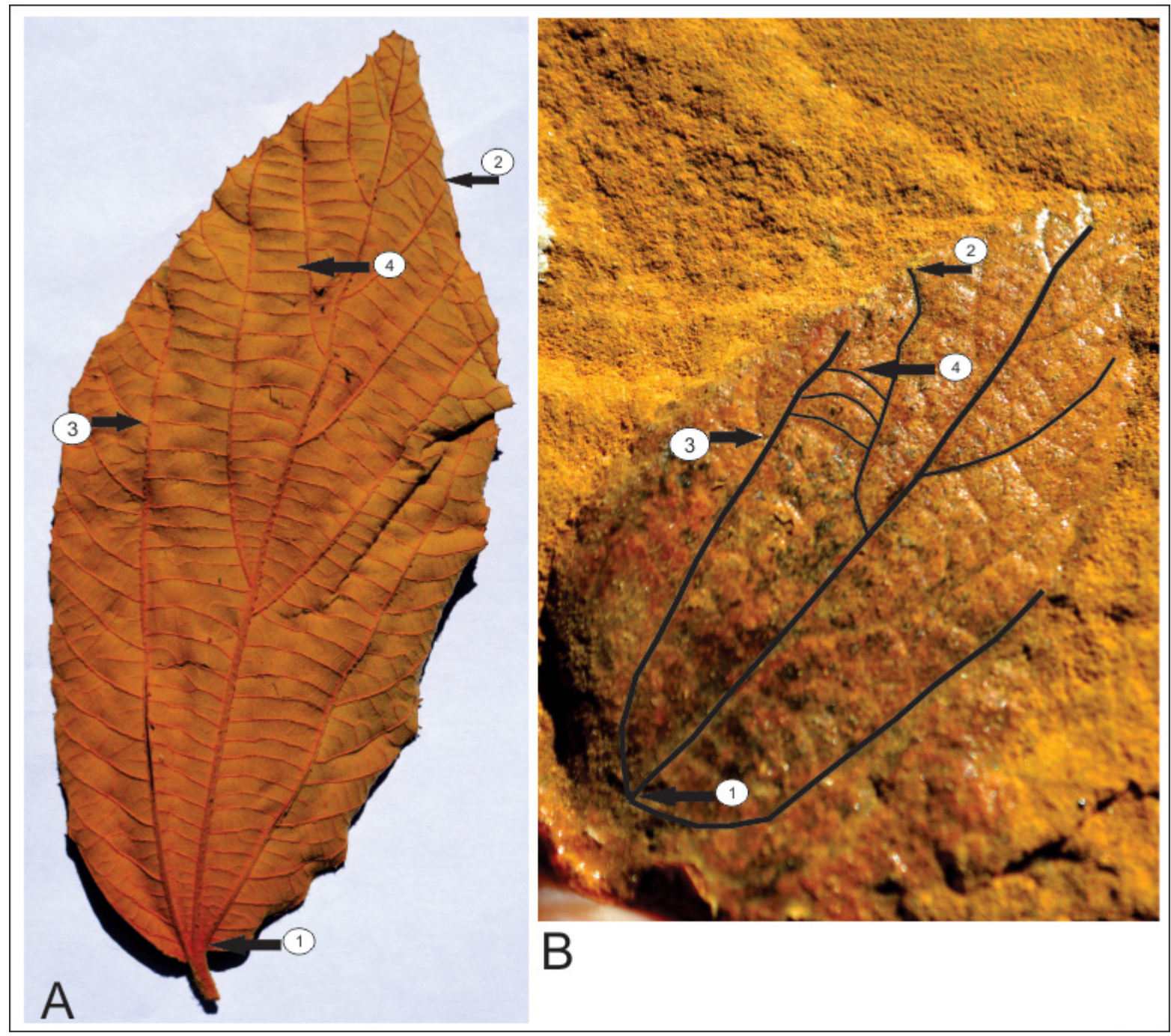

Figura 2. Ilustração da metodologia utilizada na descrição das impressões foliares; exemplo da metodologia aplicada a Luehea. A) folha atual de Luehea; B) espécime fóssil UNIR-PB-0008B; características diagnósticas numeradas: 1 - venação primária actinodódroma; 2 - venação secundária craspedódroma; 3 - uma das nervuras primárias laterais maior que a outra lateral; 4 - venação terciária.

\section{Resultados}

Os fósseis vegetais aqui analisados consistem em 10 impressões foliares, sendo que nove exemplares foram identificados como Luehea e um exemplar pertence ao gênero Theobroma. As impressões foram encontradas em afloramento situado na localidade denominada Ilha do Padre (coordenadas geográficas S 915'27,75";

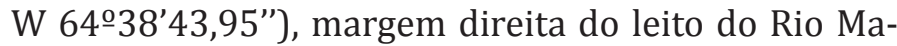
deira, na área de abrangência do AHE Jirau (Fig. 1 AB). A análise das feições deposicionais e o contexto da área permitem associar os níveis fossilíferos à Formação Rio Madeira. As impressões foliares estão inclusas em uma matriz argilosa friável, caracterizada como argila siltosa amarela - parte superior da Formação Rio Madeira sensu Quadros et al.(2006) (Fig. 1CD).

As datações radiocarbônicas (AMS $\mathrm{C}^{14}$ ) realizadas com duas amostras de sedimento procedentes da camada inferior ao estrato fossilífero, apresentaram idades de 15.910 e 14.850 anos calibrados AP, correspondendo ao Pleistoceno Superior.

Devido à preservação e com base na descrição morfológica, os espécimes foram identificados até o nível genérico. Na maioria dos espécimes o limbo não está preservado em sua totalidade, sendo que estão fragmentadas regiões de ápice, base e margem do limbo. Os espécimes UNIR-PB- 008 A e UNIR-PB-008 B estão bem preservados, e as características diagnósticas são observadas inteiramente nestes espécimes (Tabela 1). Sendo assim, o enquadramento taxonômico dos espécimes foi realizado por comparação com estes espécimes bem preservados.

\section{Divisão Magnoliophyta \\ Classe Magnoliopsida \\ Ordem Malvales}

Família Malvaceae Jussieu, 1789

Gênero Luehea F.W. Schmidt,1793

Luehea sp.

UNIR-PB-0001: Impressão foliar de folha simples, fragmento de limbo medindo $3,6 \mathrm{~cm}$ de comprimento $(L), 3 \mathrm{~cm}$ de largura na base. 0 ápice e a margem não estão preservados. A base é observada, porém está fragmentada, não sendo possível realizar medições. Apresenta três ordens de venação preservadas. A ve- 
nação primária é composta por três nervuras primárias, uma nervura principal e duas laterais (esquerda e direita). As nervuras primárias laterais estão dispostas lateralmente à nervura primária média. A nervura primária média mede $3,6 \mathrm{~cm}$ de comprimento, enquanto as nervuras primárias direita e esquerda medem de $3,6 \mathrm{~cm}$ a 3,0 cm, respectivamente. A venação primária é actinodódroma. Apresenta preservada uma nervura secundária decurrente com 1,6 cm de comprimento. As nervuras terciárias estão preservadas, sendo percurrentes, opostas e convexas. Esta impressão é contraparte do fragmento UNIR-PB-0004 B (Fig. 3A).

UNIR-PB-0002: Impressão foliar de folha simples, fragmento de limbo medindo $4 \mathrm{~cm}$ de comprimento $(L), 1,7 \mathrm{~cm}$ de largura na base e $3,0 \mathrm{~cm}$ na largura do meio da folha. 0 espécime está fragmentado no ápice e na base, e a margem do limbo também não está definida. Apresenta duas ordens de venação preservadas. Contém duas nervuras primárias definidas, seguidas de três nervuras secundárias. A nervura primária principal tem uma medida de $3,74 \mathrm{~cm}$ de comprimento. A nervura primária esquerda mede $2,9 \mathrm{~cm}$ e a direita não se encontra preservada. As nervuras secundárias são decurrentes e variam de 0,5 a 2,3 cm de comprimento (Fig. 3B).

UNIR-PB-0003: Impressão foliar de folha simples, fragmento de limbo medindo $2,9 \mathrm{~cm}$ de comprimento $(L)$ e $2 \mathrm{~cm}$ de largura na base. 0 espécime está fragmentado e não apresenta ápice, margem e base preservados. Apresenta duas ordens de venação preservadas. A nervura primária mede $2,88 \mathrm{~cm}$ de comprimento. A nervura secundária decurrente mede $1,7 \mathrm{~cm}$ de comprimento. A venação terciária não está definida. Esta impressão é parte inferior do limbo e juntamente com o fragmento UNIR-PB-0005 (parte superior do limbo) formam um indivíduo (Fig. 3C).

UNIR-PB-0004: Impressão foliar de folha simples, fragmento de limbo medindo $5,6 \mathrm{~cm}$ de comprimento (L) e $2 \mathrm{~cm}$ de largura na base e 4,1 de largura do meio da folha. 0 espécime encontra-se fragmentado no ápice e nas margens. A base, embora presente está fragmentada. Apresenta três ordens de venação preservadas. A venação primária é composta por três nervuras, uma nervura média e duas laterais (esquerda e direita). A nervura primária média mede $3,67 \mathrm{~cm}$ de comprimento, enquanto as nervuras primárias direita e esquerda medem de $5,3 \mathrm{~cm}$ a 3,8 cm respectivamente. A venação primária é do tipo actinodódroma. Apresenta uma nervura secundária decurrente com medida de $2,4 \mathrm{~cm}$ de comprimento. A venação terciária é percurrente, oposta e convexa. Esta impressão é face do fragmento UNIR-PB-0001 (Fig. 3D).

UNIR-PB-0005: Impressão foliar de folha simples, fragmento de limbo medindo $4 \mathrm{~cm}$ de comprimento $(L)$ e 3,6 cm na largura na base. Apresenta o ápice, a margem e a base do limbo não preservados. Apresenta três ordens de venação, sendo uma nervura primária, três secundárias e diversas terciárias. A nervura principal mede 3,28 cm de comprimento. As nervuras secundárias medem de 1,2 a $3 \mathrm{~cm}$ de comprimento. A venação terciária é percurrente, oposta e convexa. Esta impressão corresponde à parte superior do limbo formado pelo UNIR-PB-0003, que forma a parte inferior (Fig. 3E).

UNIR-PB-0006: Impressão foliar de folha simples,fragmento de limbo medindo 4,5 $\mathrm{cm}$ de comprimento $(L)$ e 2,5 cm de largura. 0 ápice, a base, e a margem do limbo não estão preservados. Apresenta três ordens de venação preservadas. A nervura primária média apresenta medida de $3,38 \mathrm{~cm}$. Exibe seis nervuras secundárias decurrentes bem definidas e várias terciárias. As nervuras secundárias medem de 0,6 a 3,2 $\mathrm{cm}$. A venação terciária é bastante visível, sendo percurrente, oposta e convexa (Fig. 3E).

UNIR-PB-0007: Impressão foliar de folha simples, medindo $8,5 \mathrm{~cm}$ de comprimento $(L)$ e $3,1 \mathrm{~cm}$ de largura da base e 3,6 cm de largura do meio da folha. 0 ápice encontra-se fragmentado. A margem é irregularmente serreada. A base está presente, mas fragmentada. Apresenta três ordens de venação preservadas. Possui uma nervura primária de onde todas as sete nervuras secundárias decurrentes partem; as nervuras terciárias estão bem aparentes e interligadas às secundárias. A nervura primária média possui 7,96 cm de comprimento. Avenação primária é actinodódroma. As nervuras secundárias possuem entre 0,9 a 4,1 cm de comprimento. A venação secundária é craspedódroma. A venação terciária é percurrente, oposta e convexa (Fig. 3F).

UNIR-PB-0008 A e B: Impressão foliar de folha simples, limbo inteiro de forma elíptica, simétrica, medindo 4,1 cm de comprimento $(L), 1,5 \mathrm{~cm}$ de largura na base e 1,7 cm na parte média do limbo.0 ápice é agudo formando um ângulo de 80․ A margem é irregularmente serreada. A base tem ângulo agudo com $80^{\circ}$, assimétrica, com raio esquerdo da base $(y)$ medindo $3,5 \mathrm{~mm}$ e raio direito da base $(x)$ medindo $7,5 \mathrm{~mm}$ (lado direito da base maior que o esquerdo) e formato do tipo cuneiforme. Apresenta três ordens de venação preservadas.A venação primária é composta por três nervuras primárias, uma nervura média e duas laterais (esquerda e direita). As nervuras primárias laterais estão dispostas lateralmente à nervura primária média. A nervura primária média mede $3,88 \mathrm{~cm}$ de comprimento, enquanto que as nervuras primárias direita e esquerda medem de 1,9 cm e 2,8 cm respectivamente. A venação primária é do tipo palmada, actinodódroma, basal e a nervura primária direita é maior que a esquerda. Apresenta sete nervuras secundárias decurrentes, com medidas que variam de $0,6 \mathrm{~cm}$ a 1,7 formando ângulos uniformes com a nervura média. A venação secundária é do tipo craspedódroma. A venação terciária é percurrente, oposta e convexa. (Fig. 2B, fig. 3C).

\section{Gênero Theobroma Linné Theobroma sp.}


UNIR-PB-009: Impressão foliar medindo 14,2 cm de comprimento e $1,5 \mathrm{~cm}$ de largura. Apresenta margem definida, porém o ápice e a base não estão preservados. 0 espécime analisado não possui nervura primária preservada, pois somente uma parte do lim- bo está conservada. Possui treze nervuras secundárias que medem de 1 a 3,7 cm de comprimento. A venação secundária é broquidódroma. A venação terciária é percurrente, oposta e convexa (Fig. 4).

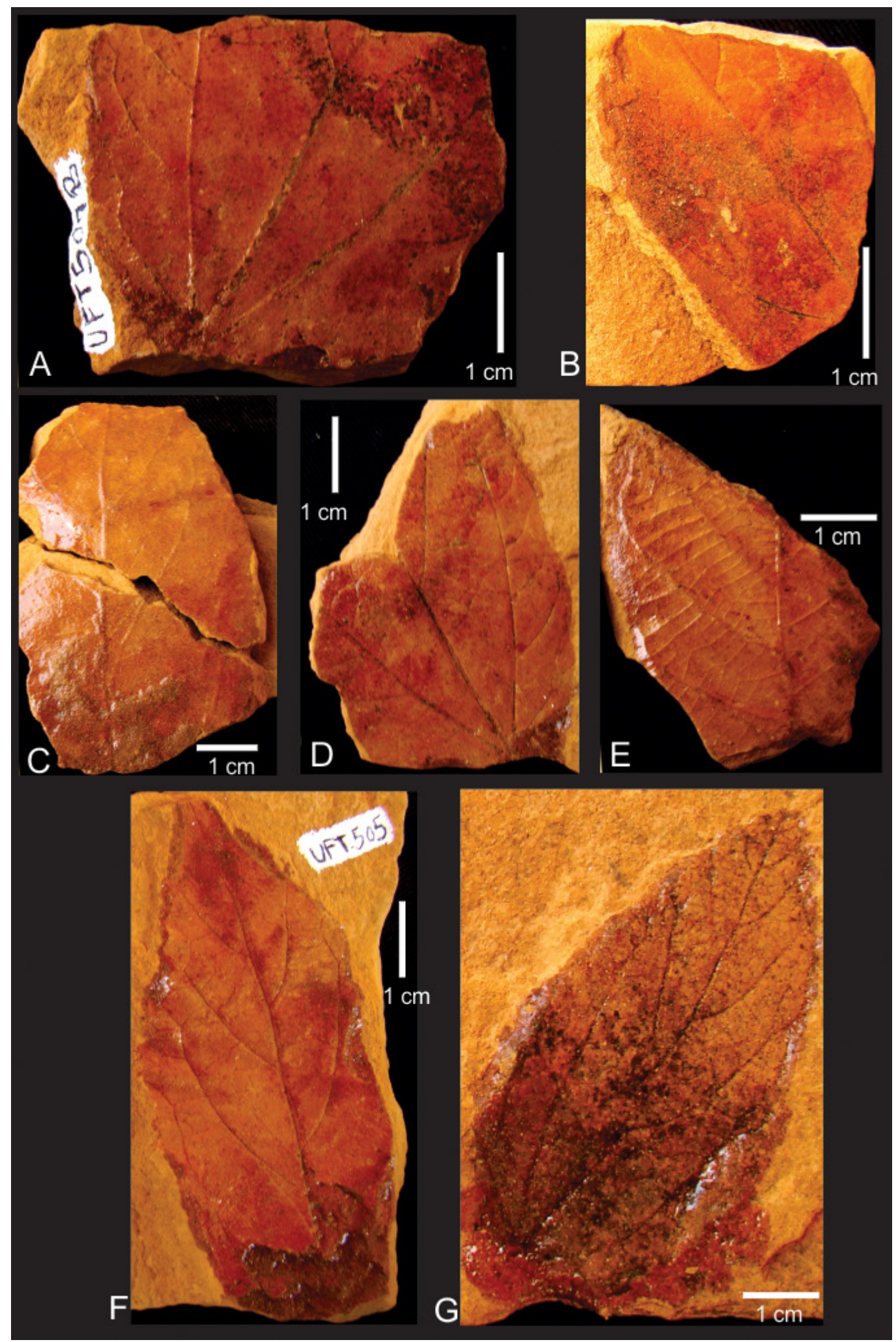

Figura 3. Impressões foliares; espécimes atribuídos ao gênero Luehea. A) UNIR-PB-0001, apresenta três nervuras primárias que saem de um único ponto da base foliar (actinodrômica); B) UNIR-PB-0002, apresentando duas nervuras primárias definidas, que partem da base, seguidas das três nervuras secundárias; C) UNIR-PB-0003 (parte inferior) e UNIR-PB-0005 (parte superior), evidenciando a nervura principal e nervura secundárias; D) UNIR-PB-0004, exibindo três nervuras primárias bem definidas, seguida de várias nervuras secundárias; E) UNIR-PB-0006, comumanervura primária bem definida e 6secundárias, onde saem as terciárias bastante marcadas; F) UNIR-PB-0007, evidenciando uma nervura primáriade onde as secundárias decurrentespartem; as nervuras terciárias estão bem aparentes e interligadas nas secundárias; G) UNIR-PB-0008, aqui explicitado somente uma das faces (A), com a demonstração das três nervuras primárias que partem de um mesmo ponto (venação actinodódroma), e as nervuras secundárias e terciárias bem definidas. 


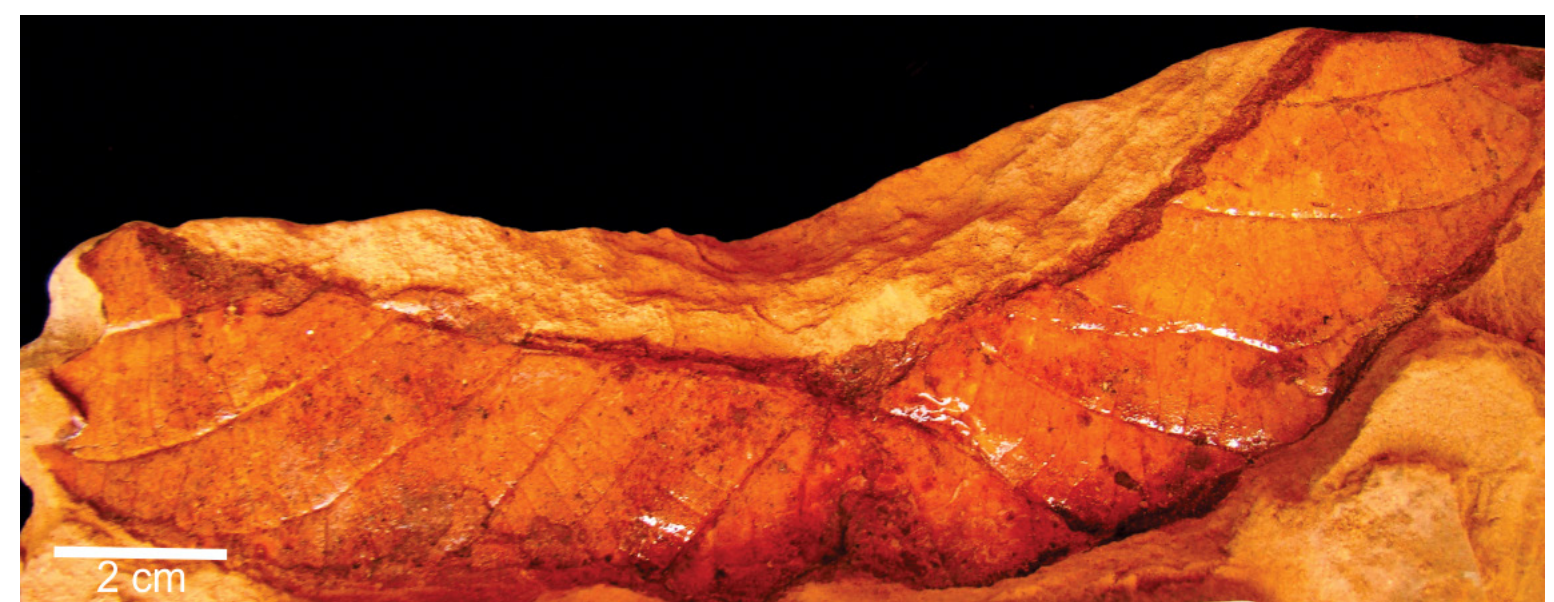

Figura 4. Amostra atribuída ao gênero Theobroma, demonstrando o tipo de venação broquidódroma; apresenta nervuras retorcidas para cima, onde as nervuras laterais divergem da nervura central em ângulo diverso e curvando-se antes de atingirem a margem.

Tabela 1. Resumo das características citadas nas descrições dos espécimes analisados; $\left(^{*}\right)$ como algumas das impressões foliares não possuem base e/ou margens preservadas, o tipo de venação não pode ser confirmado para todos os espécimes; $\mathrm{Np}=\mathrm{Não}$ preservado; $\mathrm{P}=$ Preservados.

\begin{tabular}{|c|c|c|c|c|c|c|c|c|c|c|}
\hline Material & $\begin{array}{c}\text { Comprimento } \\
\text { do limbo }(L) / \\
\text { largura da base/ } \\
\text { largura do meio } \\
\text { da folha }(\mathrm{cm})\end{array}$ & $\begin{array}{c}\text { Nervura } \\
\text { primária } \\
\text { média } \\
\text { (cm) }\end{array}$ & $\begin{array}{l}\text { Nervuras } \\
\text { primárias } \\
\text { (direita e } \\
\text { esquerda) } \\
\text { (cm) }\end{array}$ & $\begin{array}{l}\text { Nervuras } \\
\text { secundárias } \\
\text { (cm) }\end{array}$ & $\begin{array}{l}\text { Nervuras } \\
\text { terciárias }\end{array}$ & $\begin{array}{c}\text { Tipo de } \\
\text { venação } \\
\text { primária e } \\
\text { secundária }\end{array}$ & $\begin{array}{l}\text { Margem } \\
\text { do limbo }\end{array}$ & Ápice & Base & Obs. \\
\hline UNIR-PB -0001 & $3,6 / 3,0 / \mathrm{Np}$ & 3,60 & $3,6 / 3,0$ & $\begin{array}{c}\text { Uma nervura } \\
1,6\end{array}$ & $P$ & Actinodódroma & $\mathrm{Np}$ & $\mathrm{Np}$ & $\mathrm{P}$ & $\begin{array}{l}\text { Contraparte } \\
\text { de UNIR- } \\
\text { PB- } 0004\end{array}$ \\
\hline UNIR- PB -0002 & $4,0 / 1,7 / 3,0$ & 3,74 & $\mathrm{~Np} / 2,9$ & $\begin{array}{c}\text { Três nervuras } \\
1,8 / 0,5 / 2,3\end{array}$ & $\mathrm{~Np}$ & $\begin{array}{c}\text { Actinodódroma } \\
(?)\end{array}$ & $\mathrm{Np}$ & $\mathrm{Np}$ & $\mathrm{Np}$ & - \\
\hline UNIR- PB -0003 & $2,9 / 2,0 / \mathrm{Np}$ & 2,88 & $\mathrm{~Np}$ & $\begin{array}{c}\text { Uma nervura } \\
1,7\end{array}$ & $\mathrm{~Np}$ & $\begin{array}{c}\text { Actinodódroma } \\
\text { (?) }\end{array}$ & $\mathrm{Np}$ & $\mathrm{Np}$ & $\mathrm{Np}$ & $\begin{array}{c}\text { Parte } \\
\text { inferior de } \\
\text { UNIR-PB- } \\
0005\end{array}$ \\
\hline UNIR- PB- 0004 & $5,6 / 2,0 / 4,1$ & 3,67 & $5,3 / 3,8$ & Uma nervura 2,4 & $P$ & Actinodódroma & $\mathrm{Np}$ & $\mathrm{Np}$ & $P$ & $\begin{array}{l}\text { Contraparte } \\
\text { de UNIR- } \\
\text { PB- } 0001\end{array}$ \\
\hline UNIR - PB -0005 & $4,0 / 3,6 / \mathrm{Np}$ & 3,28 & $\mathrm{~Np}$ & $\begin{array}{c}\text { Três nervuras } \\
3,0 / 2,4 / 1,2\end{array}$ & $\mathrm{P}$ & $\begin{array}{c}\text { Actinodódroma } \\
(?)\end{array}$ & $\mathrm{Np}$ & $\mathrm{Np}$ & $\mathrm{Np}$ & $\begin{array}{c}\text { Parte } \\
\text { superior de } \\
\text { UNIR-PB- } \\
0003\end{array}$ \\
\hline UNIR- PB -0006 & $4,5 / 2,5 / \mathrm{Np}$ & 3,38 & $\mathrm{~Np}$ & $\begin{array}{c}\text { Seis nervuras } \\
1,7 / 1,3 / 0,6 / \\
2,6 / 3,2 / 2,8\end{array}$ & $\mathrm{P}$ & $\begin{array}{c}\text { Actinodódroma } \\
\text { (?) }\end{array}$ & $\mathrm{Np}$ & $\mathrm{Np}$ & $\mathrm{Np}$ & - \\
\hline UNIR- PB- 0007 & $8,5 / 3,1 / 3,6$ & 7,96 & $\mathrm{~Np}$ & $\begin{array}{c}\text { Sete nervuras } \\
4,1 / 2,9 / 3,8 \\
3,5 / 2,8 / 1,80,9\end{array}$ & $P$ & $\begin{array}{l}\text { Actinodódromae } \\
\text { craspedódroma }\end{array}$ & $\mathrm{P}$ & $\mathrm{Np}$ & $\mathrm{P}$ & - \\
\hline UNIR- PB- 0008 A & $4,1 / 1,5 / 1,7$ & 3,88 & $1,9 / 2,8$ & $\begin{array}{c}\text { Sete nervuras } \\
1,7 / 1,2 / 5,9 / \\
4,3 / 1,3 / 7,3 / 3,9\end{array}$ & $P$ & $\begin{array}{l}\text { Actinodódroma e } \\
\text { craspedódroma. }\end{array}$ & $\mathrm{P}$ & $\mathrm{P}$ & $P$ & $\begin{array}{l}\text { Contraparte } \\
\text { de UNIR- } \\
\text { PB-0008 B }\end{array}$ \\
\hline UNIR - PB -0008 B & $4,1 / 1,5 / 1,7$ & 3,88 & $1,9 / 2,8$ & $\begin{array}{c}\text { Sete nervuras } \\
1,7 / 1,2 / 5,9 / \\
4,3 / 1,3 / 7,3 / 3,9\end{array}$ & $P$ & $\begin{array}{l}\text { Actinodódroma e } \\
\text { craspedódroma. }\end{array}$ & $\mathrm{P}$ & $\mathrm{P}$ & $\mathrm{P}$ & $\begin{array}{c}\text { Contraparte } \\
\text { de UNIR- } \\
\text { PB- 0008A. }\end{array}$ \\
\hline Média & $4,6 / 2,32 / 2,82$ & & $3,17 / 3,06$ & & & & & & & \\
\hline UNIR -PB- 0009 & $14,2 / 1,5 / n p$ & $\mathrm{~Np}$ & $\mathrm{~Np}$ & $\begin{array}{c}\text { Treze nervuras } \\
2,0 / 3,2 /, 3,4 / \\
2,3 / 2,2 / 1,7 / \\
1,4 / 2,0 / 2,0,2,3 \\
/ 3,4 / 3,7 / 1,0\end{array}$ & $P$ & Broquidódroma & $\mathrm{P}$ & $\mathrm{Np}$ & $\mathrm{Np}$ & - \\
\hline
\end{tabular}

\section{Discussão dos resultados}

A arquitetura foliar dos espécimes assemelha-se à da família Malvaceae, sendo que nove exemplares foram identificados como Luehea (Fig. 3) e um exemplar pertence ao gênero Theobroma (Fig. 4). Como características diagnósticas da família Malvaceae, de acordo com Ribeiro et al. (1999) e Ellis et al. (2009), encontra- das nos exemplares aqui analisados, cita-se a venação primária actinodódroma, venação secundária craspedódroma e uma das nervuras primárias laterais maior que a outra nervura lateral.

Os nove espécimes atribuídos ao gênero Luehea consistem de impressões foliares com 2,9 a 8,5 cm de comprimento do limbo (média de 4,6 cm), 1,5 a 3,6 cm de largura da base do limbo (média de 2,32 cm) e 1,8 
a 4,1 cm de largura no meio da folha (média de 2,82 $\mathrm{cm})$. As impressões são caracterizadas como macrófilas segundo classificação proposta por Webb (1959). Como características diagnósticas encontradas nos espécimes analisados, citam-se: impressão de folha simples, limbo inteiro de forma elíptica e simétrico; ápice agudo; margem irregularmente serreada; base com ângulo agudo, assimétrica e formato cuneiforme; venação primária composta por três nervuras primárias, sendo uma nervura média e duas laterais (esquerda e direita); as nervuras primárias laterais estão dispostas lateralmente à nervura primária média;a venação primária é do tipo palmada (mais de uma nervura primária), actinodódroma (três nervuras divergindo radialmente a partir de um único ponto), basal (as nervuras primárias se irradiam do ponto onde estaria o pecíolo) e apresenta uma das nervuras laterais maior que a outra lateral; nervuras secundárias decurrentes, formando ângulos uniformes com a nervura primária média; venação secundária craspedódroma (nervuras secundárias terminando na margem da folha); e venação terciária percurrente, oposta e convexa.

Segundo Ellis et al. (2009), o gênero Luehea possui como características diagnósticas a venação actinodódroma e craspedódroma e a presença de uma nervura primária lateral maior que a outra nervura lateral.

Um único exemplar (UNIR-PB-009) diferiu dos demais e, embora esteja bastante fragmentado, é possível observar a venação broquidódroma (nervuras secundárias, antes de chegarem à margem, curvam-se e encontram-se com a próxima apical, formando laços). De acordo com Ellis et al. (2009), o gênero Theobroma possui como característica diagnóstica a presença de venação broquidódroma.

Segundo Purseglove (1968), o gênero Theobroma contém 22 espécies, sendo 13 espécies ocorrentes no Brasil (Esteves, 2014). 0 gênero é atribuído a árvores e arbustos que ocorrem em áreas baixas de florestas tropicais, que podem ocorrer desde a Amazônia até o Sul do México (Cuatrecasas, 1964). Dentre as espécies mais conhecidas, pode-se citar o cacau (T. cação L.) e o cupuaçu (T. grandiflorum (Willd. exSpreng.) K. Schum), sendo este último reconhecidamente amazônico (Cuatrecasas, 1964).

Bovini et al. (2014) consideram que a Família Malvaceae compreende 69 gêneros e 754 espécies presentes no Brasil. A família tem como centros de dispersão, principalmente, o Brasil (regiões Norte, Sul e Sudeste) e o sul da África, apesar de também estar presente em zonas temperadas (Rizzini, 1986; Carvalho, 2003).

A família Malvaceae compõe um grupo monofilético, e atualmente foi reclassificada com base em dados filogenéticos em quatro famílias tradicionais: Stercurliaceae, Bombacaceae, Tiliaceae, e as próprias Malvaceae (APG III, 2009).

De acordo com as características evidenciadas, os espécimes foram comparados também com gêneros da Família Ulmaceae. Algumas espécies pertencentes à família Ulmaceae (gêneros Celtis e Trema) apresentam características semelhantes às impressões enquadradas em Luehea. No entanto, Celtis possui venação broquidódroma e o pecíolo é bem maior do que o de Luehea. No mesmo sentido, Trema apresenta folhas estreito lanceoladas e bastantes serrilhadas com as nervuras secundárias com o mesmo comprimento. Soma-se a isto a presença de folhas tenras de Trema, característica que provavelmente diminui a probabilidade de fossilização (Ribeiro et al., 1999).

Registros paleontológicos da família Malvaceae no Brasil foram efetuados por Duarte (2004), que descreveu o gênero Apeiba L. no Estado do Pará, atribuindo-lhe idade miocena. Duarte \& Mandarin-de-Lacerda (1989 ab) registraram o gênero Luehea na Formação Tremembé (Oligoceno), Bacia de Taubaté, São Paulo. Mello et al. (2002) registram a ocorrência da família Malvaceae em estratos do Eoceno da Bacia de Fonseca, Minas Gerais.

Os dois gêneros aqui registrados são comuns na cobertura florestal atual na região do AHE Jirau, e as suas presenças também são confirmadas por dados palinológicos obtidos para a parte superior da Formação Rio Madeira (Rizzotto et al., 2006). Os dados polínicos sugerem também que a área as margens do Rio Madeira já era coberta, a partir do Pleistoceno Superior, por uma densa floresta tropical, muito semelhante à vegetação atual (Rizzotto et al., 2006; Meneses et al., 2012abc). Cozzuol et al. (2004) analisaram os palinomorfos de sítios paleontológicos na região de influência do AHE Jirau e indicaram a dominância de elementos palinológicos indicativos da ocorrência de floresta úmida, corroborando com o achado paleontológico aqui descrito.

Com relação à evolução da vegetação na área de estudo, a grande maioria dos trabalhos realizados é de cunho palinológico, sendo que se tem o registro de somente um trabalho com paleovertebrados que discute de forma inversa os resultados obtidos a partir da palinologia. Os dados da megafauna regional indicam a ocorrência de animais pastadores, sugerindo a presença de vegetação tipo savana a partir do Pleistoceno Superior para a área de estudo (Ranzi, 2000).

Pesquisas palinológicas das extremidades sul e sudeste da Região Amazônica, atualmente coberta por florestas em Rondônia (Absy et al., 1991) e Carajás (Van Der Hammen \& Absy, 1994), revelaram mudanças na vegetação dessas áreas, durante o Pleistoceno Superior, sendo a vegetação de savana substituída pela floresta tropical úmida. Também baseados em dados palinológicos, Rizzotto et al. (2006) estabeleceram a predominância de elementos florestais, sugerindo clima úmido.

Absy \& Van Der Hammen (1976) e Van Der Hammen \& Absy (1994) sugerem que entre 55.000 e 26.000 anos AP, no Estado de Rondônia, predominava na região uma floresta úmida. Esta floresta sofreu modificações em sua composição após 13.000 anos, com um período de paleoclima mais seco, passando a ser do- 
minada por uma vegetação com domínio de gramíneas. Logo após esse período, a vegetação retorna a condição de floresta.

Já segundo Salgado-Laboriau (1982), o clima amazônico apresentava-se há cerca de 13.000 anos AP mais seco do que o atual, predominando uma vegetação do tipo cerrado.

Segundo Sifeddine et al. (2001), a partir de 13.000 até 10.000 anos AP a floresta de Carajás apresentava uma condição de maior umidade. Isso ocorreu devido ao aumento significativo da taxa de precipitação, sendo retomada a vegetação de floresta, que apresenta um grande desenvolvimento entre 10.000 e 8.000 anos AP. Desse modo, ocorrem oscilações entre fases mais secas e fases mais úmidas.

Durante o Holoceno, a Bacia Amazônica Central e outras áreas da América do Sul apresentaram períodos secos, levando a uma mudança na vegetação, que passa a ser dominada por vegetação rasteira (campo). Estes períodos corresponderam aos intervalos 8.0004.000 anos AP, 4.200-3.500 anos AP, 2.700-2.000 anos AP e 700-400 anos AP (Absy et al., 1991; Sifeddine et al., 1994; Gouveia et al., 1997; Pessenda et al., 1998 abc; Freitas et al., 2001).

Dessa forma, considerando-se os trabalhos palinológicos realizados na região amazônica, aqui citados, pode-se generalizar que a partir do Pleistoceno Superior a vegetação da área modificou-se passando de floresta úmida para savana. Contudo, os diferentes estudos apontam que esta modificação pode ter ocorrido de pelo menos duas formas: i) savanização após 13.000 anos, retornando a condições de maior umidade (Absy \& Van Der Hammen, 1976; Van Der Hammen \& Absy, 1994) e a partir de 13.000 até 10.000 anos a floresta apresentava uma condição de maior umidade (Sifeddine et al., 2001); ii) ou ocorrência de vegetação do tipo cerrado já a cerca de13.000 anos (Salgado-Laboriau, 1982).

Todavia, há de se ponderar que estes trabalhos são pontuais, ou seja, retratam situações de áreas específicas dentro da Floresta Amazônica como um todo, e não correspondem especificamente à área aqui estudada.

Dessa forma, o registro de impressões foliares da família Malvaceae aqui apresentado permite inferir sobre a ocorrência de floresta úmida a partir do Pleistoceno Superior na área. Entretanto, como a datação foi realizada em sedimentos abaixo da camada fossilífera, obtendo idades de 15.910 e 14.850 anos calibrados AP, este estudo não pode corroborar com os modelos de evolução vegetacional aqui discutidos a partir de dados palinológicos, visto que não se pode inferir com precisão a idade da camada fossilífera.

Nesse sentido, a diversidade biológica da Bacia do Amazonas pode ser explicada pela teoria dos refúgios, causada pela alternância entre os climas úmidos e quentes durante o Quaternário. Esta teoria demonstra que em períodos glaciais secos a floresta amazônica ficou fragmentada em manchas isoladas possibilitando que eventos de especiações e vicariância atuassem sobre as populações locais de plantas e animais (Prance, 1982).

Com relação à idade da Formação Rio Madeira, Cozzuol (1999), com base na fauna local, sugere que a idade da Formação Rio Madeira não poderia ser superior ao Pleistoceno Superior, como já postulado por Adamy \& Pereira (1991).

Rizzotto et al. (2006) realizaram datações radiocarbônicas em amostras de sedimento e em lenhos, indicando uma idade atribuída ao Pleistoceno, entre e $46.310 \pm 200$ anos $27.310 \pm 200$ anos AP.

A idade atribuída ao Pleistoceno Superior para a Formação Rio Madeira não pode ser corroborada pelos dados aqui apresentados, já que as datações radiocarbônicas (AMS $\mathrm{C}^{14}$ ), realizadas com amostras de sedimento procedentes da camada inferior a este depósito, apresentaram idades de 15.910 e 14.850 anos calibrados AP. Portanto, os depósitos fossilíferos analisados são mais recentes, sendo que somente pode-se sugerir uma idade menor que 14.850 anos.

Contudo, os depósitos da Formação Rio Madeira alcançam profundidades maiores, e datações em depósitos similares na região (ainda em estudo) sugerem que a variação lateral e vertical desta formação se deu nos últimos milhares de anos (Da-Rosa et al., 2011).

\section{Conclusões}

Através de um estudo comparativo das características morfológicas das impressões foliares com os representantes atuais pode-se concluir que as impressões foliares encontradas na localidade fossilífera Ilha do Padre, área de abrangência do AHE Jirau, Rondônia, pertencem aos gêneros Luehea e Theobroma da família Malvaceae (antes Tiliaceae e Sterculiaceae, respectivamente). Datações radiocarbônicas (AMS $\mathrm{C}^{14}$ ) realizadas em amostras de sedimento de camada inferior à camada de onde foram extraídas as impressões foliares indicam uma idade de 15.910 e 14.850 anos calibrados AP. Portanto, os depósitos sedimentares analisados da parte superior da Formação Rio Madeira formaram-se mais recentemente, sugerindo que a deposição desta formação se deu em um período maior, desde o Pleistoceno Superior. A indicação dos citados gêneros para o sudoeste amazônico sugere a presença de uma floresta tropical úmida, há pelo menos 14 mil anos.

Agradecimentos - Os autores agradecem à Energia Sustentável do Brasil, pela permissão para publicação. À família Basílio, pelo acolhimento em Jaci Paraná (RO) durante a realização deste trabalho. Ao colaborador Daniel de Freitas Nunes pelo apoio na confecção das figuras e mapas. Aos revisores anônimos e a revisora Simone Carolina Sousa e Silva, que muito contribuíram para a melhoria do manuscrito.

\section{Referências}

Absy, M.L. \& Van Der Hammen. T. 1976. Some paleoecological data from Rondônia, Southern part of the Amazon Basin. Acta Amazônica, 3: 293-299. 
Absy, M.L., Cleef, M., Fournier, A., Martin, L., Servant, M., Sifeddine, A., Silva, M.F.S., Soubies, F.I., Suguio, K., Turcq, B. \& Hammen, T.V.D. 1991. Mise en évidence de quatre phases d'ouverture de la forêt dense dans le sud-est de l'Amazonie au cours des 60.000 dernières années. Première comparaison avec d'autres regions tropicales. Comptes rendus de l'Académie des Sciences, 312(3): 673-678.

Adamy, A. \& Romanini, S.J. 1990. Geologia da Região de Porto Velho - Abunã. Porto Velho, DNPM/CPRM, 273p. (Relatório Final).

Adamy, A. \& Pereira, L.A.C. 1991. Projeto Ouro e Gemas: Frente Rondônia. Porto Velho, CPRM, 8-35p. (Relatório Anual)

APG III. 2009. An update of the Angiosperm Phylogeny Group classification for the orders and families of flowering plants: APG III. Botanical Journal of the Linnean Society, 161: 105-121.

Bahia, R.B.C. \& Pedreira, A.J. 2007. A sedimentação proterozóica (esteniana-toniana) na borda oeste do Cráton Amazônico. Revista Brasileira de Geociências, 37(2): 268-280.

Bovini, M.G., Esteves, G. \& Duarte, M.C. 2014. Malvaceae Lista de Espécies da Flora do Brasil. Jardim Botânico do Rio de Janeiro. Disponível em: <http://floradobrasil.jbrj. gov.br/jabot/floradobrasil/FB156>. Acesso em: 03 Mai. 2014.

Carvalho, P.E.R. 2003. Espécies arbóreas brasileiras. Brasília, DF: Embrapa Informação Tecnológica; Colombo: Embrapa Florestas, v.1, 1039p. (Coleção Espécies Arbóreas Brasileiras).

Costa, M.L. 1991. Os Mucururus de Rondônia: Considerações mineralógicas e geoquímicas. In: SIMPÓSIO DE GEOLOGIA DA AMAZÔNIA, 3., 1991, Belém. Anais... Belém, SBG, p. 464-478.

Cozzuol, M.A. 1999. Mamíferos acuáticos y la antigüidad de los de depositados quaternários del Alto Río Madeira (Rondônia, Brasil). In: CONGRESO INTERNACIONAL EVOLUCIÓN NEOTROPICAL DEL CENOZOICO, 18., 1999, La Paz. Anais...La Paz, p.18.

Cozzuol, M.A., Holanda, E.C., Nascimento, E.R. \& Weiss, F.L. 2006. Registro do gênero Neochoerus (Rodentia, Caviomorpha, Hydrochoeridae) para o Pleistoceno Superior da Amazônia Sul-Ocidental. Paleontologia em Destaque, 53: 43-44.

Cozzuol, M.A., Latrubesse, E.M. \& Silva, S.A.F. 2004. Estudo de viabilidade para implementação de usinas hidrelétricas no Rio Madeira. Porto Velho, UNIR/RIOMAR/FURNAS, 56p. (Relatório inédito).

Cuatrecasas, J. 1964. Cacao and its allies: a taxonomic revision of the genus Theobroma. Contributions from the United States National Herbarium, 35(6): 379-614.

Culf, A.D., Esteves, J.L., Marques Filho, A. de O. \& Da Rocha, H.R. 1996. Radiation, temperature and humidity over forest and pasture in Amazônia. In: Gash, J.H.C., Nobre, C.A., Roberts, J.M. \& Victoria, R.L. (Eds.). Amazonian Deforestation and Climate. London, John Wiley \& Sons, p.175-192.

Da-Rosa, A.A.S., Leal, L.A., Pires, E.F., Sayão, J.M., Scherer, C.S., Ilha, A.L.R., Souza, F.E., Benício, J.R.W., Silva, J.A., Campos, L., De Paula, M., Boelter, R.A., Novaes, T. \& De Souza, T. 2011. Resultados preliminares do Projeto Executivo do Programa de Investigação, Salvamento e Monitoramento Paleontológico do AHE Jirau. In: SIMPÓSIO DE GEOLOGIA DA AMAZÔNIA, 12., 2011, Boa Vista. Boletim...BoaVista, SBG, CD-ROM.

Duarte, L.2004. Paleoflórula. In: Rossetti, D.F. \& Góes, A.M. (Eds.). O Neógeno da Amazônia Oriental. Belém, Editora do Museu Paraense Emílio Goeldi, p.169-196.

Duarte, L. \& Mandarin-de-Lacerda, A.F. 1989a. Flora Cenozóica do Brasil: Fm. Tremembé. Bacia de Taubaté, SP I: Celastraceae, Loganiaceae e Thyphaceae. Anais da Academia Brasileira de Ciências, 64(1): 29-41.

Duarte, L. \& Mandarim-de-Lacerda, A.F. 1989b. Flora cenozóica do Brasil, Bacia de Taubaté, SP II: Luehea nervaperta sp. n. (Tiliaceae). In: CONGRESSO BRASILEIRO DE PALEONTOLOGIA, 11., 1989, Curitiba. Anais... Curitiba, SBP, v. 1, p. 383-394.

Ellis, B., Daly, C.D., Hickey, L.J., Johnson, K.R., Mitchell, J.D., Wilf, P. \& Wing, S. 2009. Manual of leaf architecture. New York, The New York Botanical Garden Press, 188p.

Esteves, G. 2014. Theobroma - Lista de Espécies da Flora do Brasil. Jardim Botânico do Rio de Janeiro. Disponível em: <http://floradobrasil.jbrj.gov.br/jabot/floradobrasil/ FB23617> . Acesso em: 03 Mai. 2014.

Ferraz, S.F.B., Vettorazzi, C.A., Theobald, D.M. \& Balleste, M.V.R. 2005. Landscape dynamics of Amazonian deforestation between 1984 and 2002 in central Rondônia, Brazil: assessment and future scenarios. Forest Ecology and Management, 204: 67-83.

Freitas, H.A., Pessenda, L.C.R., Aravena, R., Gouveia, S.E.M., Ribeiro, A.S. \& Boulet, R. 2001. Late Quaternary vegetation dynamics in the Southern Amazon Basin inferred from carbon isotopes in soil organic matter. Quaternary Research, 55: 39-46.

Góis, F. 2005. Estudo descritivo e geométrico dos Cingulata (Mammalia, Xenarthra) do Neógeno e Quarternário da Amazônia Sul-Ocidental. Porto Velho, 58p. Monografia de Conclusão de Curso, Ciências Biológicas, Universidade Federal de Rondônia.

Góis, F., Nascimento, E.R., Porto, A.S., Holanda, E.C. \& Cozzuol, M.A. 2004. Ocorrências de Cingulata dos gêneros Kraglievichia e Holmesina do Terciário e Quaternário da Amazônia Sul-Ocidental. Ameghiniana, 41(4): 49.

Góis, F. \& ScillatoYané, G.J. 2008. Un novedoso pampatérido (Xenarthra, Glyptodontoidea, Pampatheriidae) del Pleistoceno de Rondônia, sudoeste de la Amazonia, Brasil. In: CONGRESSO LATINO AMERICANO DE PALEONTOLOGIA DE VERTEBRADOS, 3., 2008, Neuquén. Resúmenes... Neuquén, p.113.

Góis, F., ScillatoYané, G.J., Carlini, A.A. \& Ubilla, M. 2012. Una nueva especie de Holmesina Simpson (Xenarthra, Cingulata, Pampatheriidae) del Pleistoceno de Rondônia, sudoeste de la Amazonia, Brasil. Revista Brasileira de paleontología, 15(2):211-227.

Gouveia, S.E.M., Pessenda, L.C.R., Aravena, R., Boulet, R., Roveratti, R. \& Gomes, B.M. 1997. Dinâmica de vegetações durante o Quaternário recente no sul do Amazonas indicada pelos isótopos do carbono (12C, 13C e 14C). Geochimica Brasiliensis, 11(3): 355-367.

Holanda, E.C. 2007. Os Tapiridae (Mammalia, Perissodactyla) do pleistoceno superior do estado de Rondônia. Porto Alegre, 79p. Dissertação de mestrado, Programa de Pós-Graduação em Geociências, Universidade Federal do Rio Grande do Sul.

Holanda, E.C. \& Cozzuol, M. 2005. Análise morfométrica de dentários de Tapirus (Mammalia, Perissodactyla) do Pleistoceno Superior da Amazônia Sul-Ocidental, Brasil. Paleontologia em Destaque (Boletim Informativo da Sociedade Brasileira de Paleontologia), 49: 8.

Holanda, E.C. \& Cozzuol, M. 2006. New records of Tapirus from the Pleistocene of Southwestern. Revista Brasileira 
de Paleontologia, 9(2): 193-200.

Holanda, E.C., Ferigolo, J. \& Ribeiro, A.M. 2011. New Tapirus species (Mammalia: Perissodactyla: Tapiridae) from the upper Pleistocene of Amazonia, Brazil. Journal of Mammalogy, 92: 111-120.

Holanda, E.C., Porto, A.S., Nascimento, E.R., Góis, F. \& Cozzuol, M. 2004. Registros do gênero Tapirus (Mammalia, Perissodactyla) do Pleistoceno da Amazônia Sul-Ocidental. Ameghiniana, 41(4): 51.

IBGE. Instituto Brasileiro de Geografia Estatística. 1992. Manual técnico da vegetação Brasileira. Rio de Janeiro, 275p.

Mello, C. L., Sant'Anna, L.G. \& Bergquist, L.P. 2002. Vegetais Fósseis do Terciário Brasileiro - SIGEP 86. In: Schobbenhaus, C., Campos, D.A., Queiros, E.T., Winge, M. \& Berbert-Born, M. (Eds.). Sítios Geológicos e Paleontológicos do Brasil. Brasília, SIGEP, 86(1): 73-79.

Meneses, M.E.N.S., Pires, E.F., Da-Rosa, A.A.S., Leal, L.A., Mendes, L.A.S., De Paula, M.J., Souza, F.E.F., Benício, J.R.W. \& Campos, L.S. 2012a. Registro palinológico de depósitos sedimentares do Rio Madeira na região de abrangência do AHE Jirau, Rondônia, norte do Brasil. In: CONGRESSO BRASILEIRO DE GEOLOGIA, 46.,2012, Rondônia. Boletim... Rondônia, SBG, CD-ROM.

Meneses, M.E.N.S., Pires, E.F., Da-Rosa, A.A.S., Leal, L.A., Mendes, L.A.S., De Paula, M.J., Souza, F.E.F., Benício, J.R.W. \& Campos, L.S. 2012b. Registro palinológico de depósitos sedimentares neopleistocênicos do Rio Madeira, Rondônia, Amazônia Brasileira. Revista do Instituto Geológico, 33(2), 41-48.

Meneses, M.E.N.S., Pires, E.F., Da-Rosa, A.A.S., Mendes, L.A.S., De Paula, M., Silva, F.E.F. \& Benício, J.R.W. 2012c. Fossil and modern pollen from Madeira River basin in the area of influence of the AHE Jirau, Rondonia State, Brazil. In: ANNUAL MEETING OF ASSOCIATION OF TROPICAL BIOLOGY AND CONSERVATION, 49., 2012, Bonito. MS. Anais...Bonito, p. 325.

Nascimento, E.R. 2008. Os Xenartra pilosa (Megatheridae), Notoungulata (Toxodontidae) e Proboscidae (Gomphoteriidae) da Formação Rio Madeira, Pleistoceno Superior, Estado de Rondônia, Brasil. Porto Alegre, 113p. Dissertação de Mestrado, Programa de Pós-Graduação em Geociências, Universidade Federal do Rio Grande do Sul.

Nascimento, E.R. \& Holanda, E.C. 2006. Considerações paleombientais sobre a Formação Rio Madeira, Pleistoceno Superior- Rondônia. In: SEMANA ACADÊMICA DOS ALUNOS DE PÓS-GRADUAÇÃO EM GEOCIÊNCIAS, 1., 2006 Porto Alegre. Boletim... Porto Alegre, UFRGS, p. 105-108.

Nascimento, E.R., Porto, A.S., Holanda, E.C., Góis, F. \& Cozzuol, M.A. 2003. A fauna local de mamíferos pleistocênicos das localidades de Araras/Periquitos e Taquara, Rondônia. In: CONGRESSO BRASILEIRO DE PALEONTOLOGIA, 18. 2003, Brasília. Boletim... Brasília, SBP, p. 206-207.

Nascimento, E.R., Holanda, E.C., Góis, F.L. \& Cozzuol, M.A. 2005. Inferências paleoambientais para depósito fossilíferos do Quaternário da Amazônia sul- Ocidental, Brasil. In: CONGRESSO BRASILEIRO DE PALEONTOLOGIA, 19. 2005, Aracajú. Boletim... Aracajú, SBP, CD-ROM.

Nascimento, E.R., Tizuka, M.M., Bissaro Júnior, M.C. \& Kipnis, R. 2009. Registro de restos vegetais fósseis e o seu contexto estratigráfico, canteiro de obras da UHE Santo Antônio, Porto Velho - RO. In: CONGRESSO BRASILEIRO DE PALEONTOLOGIA, 21., 2009, Belém. Boletim... Belém, SBP, CD-ROM.

New York Botanical Garden, 2013. Disponível em: <http:// www.nybg.org/>. Acesso em: 05 dez. 2013.

Pessenda, L.C.R., Gouveia, S.E.M., Aravena, R., Gomes, B.M., Boulet, R. \& Ribeiro, A.S. 1998a. ${ }^{14} \mathrm{C}$ dating and stable carbon isotopes of soil organic matter in forest-savanna boundary areas in Southern Brazilian Amazon Region. Radiocarbon, 40: 1013-1022.

Pessenda, L.C.R., Gomes, B.M., Aravena, R., Ribeiro, A.S., Boulet, R. \& Gouveia, S.E.M. 1998b. The carbon isotope record in soils along a forest-cerrado ecosystem transect: implication for vegetation changes in Rondônia State, southwestern Brazilian Amazon region. The Holocene, 8: 631-635.

Pessenda, L.C.R., Lisi, C.S, Gouveia, S.E.M. 1998c. Datação por ${ }^{14}$ C. In: Pessenda, L.C.R. (Org.) Laboratório de ${ }^{14}$ C.Técnicas e aplicação paleoambientais. Piracicaba: CENA/USP, p. 3-5.

Prance, G.T. 1982. Biological Diversification in the Tropics. New York, Columbia Univer. Press, 714p.

Purseglove, J. W. 1968. Tropical crops-dicotyledons. London, Longman Green, v.1, 332 p.

Quadros, M.L.E.S., Rizzotto, G.J., Oliveira, J.G.F. \& Castro, J.M.R. 2006. Depósitos fluviais da Formação Rio Madeira, Pleistoceno Superior da Bacia do Abunã, Rondônia. In: SIMPÓSIO DE GEOLOGIA DA AMAZÔNIA, 9., 2006, Belém. Boletim... Belém, SBG. 1 CD-ROM.

Quadros, M.L.E.S. \& Rizzotto, G.J. 2007. Geologia e recursos minerais do Estado de Rondônia. Sistema de Informações Geográficas- SIG: Texto explicativo do Mapa Geológico e de Recursos minerais do Estado de Rondônia, Porto Velho, CPRM, escala 1:1.000.000, 153 p.

RADAMBRASIL. 1978. Levantamento de Recursos Naturais. Folha SC-20. Porto Velho, DNPM, 663p.

Ranzi, A. 2000. Paleoecologia da Amazônia: Megafauna do Pleistoceno. Florianópolis, Editora da Universidade Federal de Santa Catarina, 122p.

Ribeiro, J.E., Hopkins, M.J.G., Vicentini, A., Sothers, C. A., Costa, M., Brito, M., Souza, M., Martins, L.H., Lohmann, L., Assunção, P.A., Pereira, E., Silva, C. F., Mesquita, M. \& Procópio, L. 1999. Flora da Reserva Ducke: Guia de identificação de uma floresta de terra firme na Amazônia Central. Manaus, Editora do INPA, 816p.

Rizzini, C.T. 1986. Árvores e madeiras úteis do Brasil: manual de dendrologia brasileira. São Paulo, Edgard Blucher, $296 \mathrm{p}$.

Rizzotto, G.J. 2005. Projeto Rio Madeira: Levantamento de informações para subsidiar o estudo de viabilidade do aproveitamento hidrelétrico (AHE) do Rio Madeira. AHE Jirau. Porto Velho, CPRM, 213p. (Relatório Final).

Rizzotto, G.J., Cruz, N.M.C., Oliveira, J.G.D., Quadros, M.L.E.S. \& Castro, J.M. 2006. Paleoambiente e o registro fossilífero Pleistocênico dos sedimentos da Formação Rio Madeira. In: SIMPÓSIO DE GEOLOGIA DA AMAZÔNIA, 9., 2006, Belém. Anais... Belém, SBG. 1 CD-ROM.

Sadeck, F.J. 1999. Sobre a ocorrência de fósseis em ArarasDivisão de Minas e Controle Ambiental na Mineração. Brasília, DNPM, 18p.

Salgado-Laboriau, M.L. 1982. Climatic changes at the Pleistocene-Holocene boundary. In: Prance, G.T (Ed.). Biological Diversification in the tropics. New York, Columbia University Press, p. 74.

Sant'Anna Filho, M.J., Trindade, A. \& Marques, G.M. 1996. Mamíferos fósseis do Quaternário de Rondônia. In: Latrubesse, E. (Ed.).Paleo e neoclimas da Amazônia Sul-Ocidental. Rio Branco, UFAC/LGS, p. 26-37. 
Sant'Anna Filho, M.J. \& Schmitt, J.R. 1999. Achados inéditos de mamíferos fósseis do Pleistoceno/Holoceno em garimpos no paleo leito do rio Madeira do Estado de Rôndonia. In: CONGRESSO BRASILEIRO DE PALEONTOLOGIA, 16., 1999, Crato. Boletim... Crato, SBP, p.110.

Sant'Anna Filho, M.J. \& Vidal, D.A. 1999. Ocorrência de Mixotoxodonlarensis (Toxodontidae, Mammalia) em sedimentos do paleoleito do rio Madeira no Estado de Rondônia, Brasil. In: CONGRESSO BRASILEIRO DE PALEONTOLOGIA, 16., 1999, Crato. Boletim... Crato, SBP, p.112.

Sifeddine, A., Fröhlich, F., Fournier, M., Martin, L., Servant, M., Soubiés, F., Turco, B., Suguio, K. \& Volkmer-Ribeiro, C. 1994. La sédimentation lacustre indicateur de changements dês paléoenvironements au cours des 30000 dernières années (Carajas, Amazonie, Brésil). Compte Rendus de I'Academie dês Sciences, 318(2): 1645-1652.

Sifeddine, A., Martin, L., Turcq, B., Ribeiro, C.V., Soubiés, F., Cordeiro, R.C. \& Suguio, K. 2001. Variations of the Amazonian rainforest environment: a sedimentological record

Manuscrito 530.

Editores: Tatiana Silva da Silva \& Paulo A. Souza. covering 30,000 years. Palaeogeography, Palaeoclimatology, Palaeoecology, 168: 221-235.

Silva, K.S., Rosa, J.H. \& Luz, R.A. 2010. Carta de sensibilidade arqueológica: breve introdução aos estudos de padrões de assentamento de populações pré-colombianas na UHE Jirau - Rondônia, Brasil. Revista de Geografia, 2: 264-278.

Van Der Hammen, T. \&Absy, M.L. 1994. Amazonia during the last glacial. Paleogeography, Paleoclimatic, Paleoecology, 109: 247-261.

Von Randown, C., Manzi, A.O., Kruijt, B., Oliveira, P.J., Zanchi, F.B., Silva, R.L., Hodnett, M.G., Gash, J.H.C., Elbers, J.A., Waterloo, M.J., Cardoso, F.L. \& Kabat, P. 2004. Comparative measurements and seasonal variations in energy and carbon exchange over forest and pasture in South West Amazonia. Theorical and Applied Climatology, v. especial: 1-22.

Webb, L.J.1959. A plysiognomic classification of Austalian rain forests. Journal of Ecolog ,47:551-570. 
